\title{
Susceptibilidade de animais de laboratório à intoxicação por Ateleia glazioviana (Leg. Papilionoideae) ${ }^{1}$
}

\author{
Lenir G. Leite ${ }^{2}$, Franklin Riet-Correa ${ }^{3}$, Rosane M. T. Medeiros ${ }^{3}$, Andrea Piacenti ${ }^{4}$, \\ Marcos Aragão ${ }^{4}$ e Sandro V. Schons ${ }^{2}$
}

\begin{abstract}
Leite L. G., Riet-Correa F., Medeiros R.M.T., Piacenti A., Aragão M. \& Schons S.V. 2002. [Susceptibility of laboratory animals to the intoxication by Ateleia glazioviana (Leg. Papilionoideae).] Susceptibilidade de animais de laboratório à intoxicação por Ateleia glazioviana (Leg. Papilionoideae). Pesquisa Veterinária Brasileira 22(2):73-78. Laboratório Regional de Diagnóstico, Faculdade de Veterinária, Universidade Federal de Pelotas, 96010-900 Pelotas, RS, Brazil. E-mail: lgmv@alternet.com.br

Rabbits, guinea pigs, rats and mice were used to reproduce the cardiac lesions observed in ruminants in the intoxication by Ateleia glazioviana. Four animals of each species were fed during four months with a ration containing $10 \%$ of dry A. glazioviana. The pellets were made by mixing $700 \mathrm{~g}$ of commercial ration, $200 \mathrm{~g}$ of cornstarch, $1000 \mathrm{ml}$ of distilled water and 100 $\mathrm{g}$ of the dry plant. Later this mixture was dried at $100^{\circ} \mathrm{C}$ during $16-20$ hours. Four control animals of each species were given similar food, but containing dry ryegrass (Lolium multiflorum) instead of A. glazioviana. Water was offered ad libitum and a daily amount of green oats (Avena sativa) was given to rabbits and guinea pigs. No clinical signs of disease were observed during the experiment. All animals were weighted weekly in the last 5 weeks of the experiment and no differences were observed in weight gains between treated and control groups. At the end of dosing all animals were euthanatized and necropsied. No macroscopic or histologic lesions were observed in the heart or other organs. The abortive properties of A. glazioviana were studied in rats. One group of 11 pregnant rats was fed, from day 7 to day 21 of gestation, ration containing $10 \%$ of $A$. glazioviana, prepared in the same way than in the previous experiment. A control group received the ration with $10 \%$ ryegrass. All rats delivered normal litters. To determine a possible loss of toxicity of the plant during the pellet preparation, dry A. glazioviana was heated for $16-20$ hours at $100^{\circ} \mathrm{C}$ and administered orally to one ewe. This sheep ingested daily $2.65 \mathrm{~g} / \mathrm{kg}$ bw of dry A. glazioviana for 26 days. During the experimental period the animal had tachycardia and cardiac arrhythmia. At the end of the experiment bradycardia and severe depression were observed. It was euthanatized 7 days after the last plant administration. The sheep was 2.5-3 months pregnant and the fetus was apparently normal with no autolysis. Ascites and hydrothorax were observed at necropsy. Whitish areas were observed in the myocardium and the liver was pale. Degeneration and necrosis of cardiac fibers and proliferation of fibrous tissue were observed histologically in the heart. The liver had centrilobular degeneration of hepatocytes and congestion. These experiments indicate that A. glazioviana is not cardiotoxic for laboratory animals and suggest that the plant has a heat-stable active principle similar to the active principle of plants causing cardiac fibrosis (gousiekte) in Southern Africa.
\end{abstract}

INDEX TERMS: Ateleia glazioviana, toxic plants, abortion, cardiac failure.

\footnotetext{
${ }^{1}$ Aceito para publicação em 16 de maio de 2002.

Trabalho apoiado pelo Programa de Apoio a Grupos de Excelência (PRONEX).

Parte da tese de Mestrado do primeiro autor, no Programa de Pós-Graduação em Medicina Veterinária, Faculdade de Veterinária, Universidade Federal de Pelotas.

${ }^{2}$ Faculdade de Veterinária, Centro de Ciências Rurais, Universidade da Re-
}

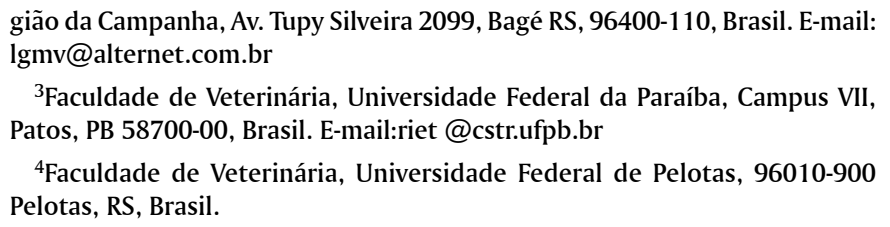

gião da Campanha, Av. Tupy Silveira 2099, Bagé RS, 96400-110, Brasil. E-mail: lgmv@alternet.com.br

${ }^{3}$ Faculdade de Veterinária, Universidade Federal da Paraíba, Campus VII, Patos, PB 58700-00, Brasil. E-mail:riet @cstr.ufpb.br

${ }^{4}$ Faculdade de Veterinária, Universidade Federal de Pelotas, 96010-900 Pelotas, RS, Brasil. 
RESUMO.- Coelhos, cobaias, ratos e camundongos foram utilizados com a finalidade de reproduzir a forma cardíaca da intoxicação por Ateleia glazioviana. Quatro animais de cada espécie receberam por 4 meses a planta, secada à sombra, na concentração de $10 \%$ na ração, fornecida na forma de pelets. Os pelets foram preparados misturando $700 \mathrm{~g}$ de ração comercial, $200 \mathrm{~g}$ de amido de milho, $1000 \mathrm{ml}$ de água destilada e $100 \mathrm{~g}$ de planta seca e, posteriormente, secados em estufa a $100^{\circ} \mathrm{C}$, durante 16 a 20 horas. Quatro animais de cada espécie serviram como testemunhas, recebendo a ração preparada da mesma forma, porém com a utilização de azevém (Lolium multiflorum) em lugar de A. glazioviana. Era fornecida água à vontade e, para os coelhos e cobaias, também aveia (Avena sativa) verde diariamente. Esses animais não apresentaram nenhuma alteração clínica, e foram pesados semanalmente nas últimas 5 semanas do período experimental, não apresentando diferença significativa no ganho de peso. Ầ necropsia não foram observadas alterações macroscópicas e pelo exame histológico também não foram detectadas lesões significativas no coração e em outros órgãos. Para testar a atividade abortiva de $A$. glazioviana, ração contendo $10 \%$ de planta seca, preparada da mesma forma que no experimento anterior, foi administrada a 11 outros ratos, fêmeas, prenhes, nos dois últimos terços da gestação. Um grupo controle de 11 fêmeas recebeu a ração com azevém a 10\%, durante o mesmo período. Esses animais tiveram filhotes normais e no prazo correto. Para determinar a possível perda de toxidez da planta durante a preparação dos pelets, $A$. glazioviana foi aquecida por 16 a 20 horas a $100^{\circ} \mathrm{C}$ e, posteriormente, administrada a um ovino em 26 doses diárias de $2,65 \mathrm{~g} / \mathrm{kg}$ de planta seca. Durante o período experimental, a ovelha apresentou batimentos cardíacos mais fortes, taquicardia e arritmia cardíacas, depois bradicardia e, no período final, apatia acentuada. Foi sacrificada 7 dias após a última administração da planta. Esse animal apresentava gestação de 2,5 a 3 meses e o feto não apresentava sinais de autólise. As alterações macroscópicas mais evidentes à necropsia foram ascite, hidrotórax, áreas esbranquiçadas no músculo cardíaco e figado de coloração clara. Na histologia do coração foram observadas degeneração e necrose de fibras cardíacas e proliferação de tecido conjuntivo fibroso. $O$ fígado apresentava congestão e degeneração de hepatócitos nas áreas centrolobulares. Os resultados indicam que esses animais de laboratório não foram susceptíveis à ação cardiotóxica de $A$. glazioviana, por via oral, e sugerem a possibilidade de que $o$ princípio ativo da planta, que é resistente ao calor, seja semelhante ao princípio ativo das plantas do sul da África que causam fibrose cardíaca.

TERMOS DE INDEXAÇÃO: Ateleia glazioviana, plantas tóxicas, aborto, insuficiência cardíaca.

\section{INTRODUÇÃO}

A intoxicação por Ateleia glazioviana provoca em bovinos, no Oeste de Santa Catarina e Noroeste do Rio Grande do Sul, sinais clínicos nervosos e cardiovasculares. Nesses casos, as principais lesões histológicas observadas incluem tumefação e necrose de miofibras cardíacas, fibrose do músculo cardíaco, congestão centrolobular e fibrose do fígado, além de degeneração esponjosa da substância branca do encéfalo (status spongiosus). Podem ocorrer casos de morte súbita ou ser observada uma sintomatologia caracterizada por edemas de declive, ingurgitamento das veias jugulares e pulso venoso positivo, precedida ou não por apatia, letargia e cegueira, acometendo principalmente bovinos com mais de um ano de idade (Gava \& Barros 2001, Gava et al. 2001).

É descrita, também, uma forma abortiva da enfermidade, atingindo vacas em qualquer período gestacional, sendo que quando a ingestão da planta ocorre no final da gestação, nascem bezerros fracos que geralmente morrem em poucos dias (Stolf et al. 1994).

A. glazioviana é conhecida como uma planta ictiotóxica que, por causar morte ou imobilização dos peixes, tem sido utilizada pelos nativos para auxiliar na pesca (Ortega \& Schenkel 1987).

A determinação da susceptibilidade dos animais de laboratório a plantas tóxicas para ruminantes e eqüinos é necessária para o estudo dessas plantas. Isto porque a utilização de animais de laboratório propicia um modelo experimental para testar a toxicidade das substâncias isoladas das plantas e determinar o princípio ativo e a patogenia das mesmas. Este trabalho foi desenvolvido com o objetivo de testar a susceptibilidade de animais de laboratório à intoxicação por A. glazioviana, avaliando possíveis alterações clínicas, macroscópicas ou microscópicas, semelhantes àquelas observadas em ovinos e bovinos, a fim de viabilizar estudos experimentais com espécies de laboratório.

\section{MATERIAL E MÉTODOS}

\section{Efeito cardiotóxico em animais de laboratório}

Com o objetivo de reproduzir a forma cardíaca da intoxicação por A. glazioviana, foram utilizados 32 animais, sendo oito coelhos, oito cobaias, oito ratos e oito camundongos, todas fêmeas, não prenhes, em idade adulta. Os animais permaneceram em gaiolas, por 4 meses, ficando quatro animais em cada gaiola (cobaias, ratos e camundongos) ou dois animais em cada gaiola (coelhos), identificando-se um grupo de quatro animais como experimentais e outro grupo de quatro animais como testemunhas, para cada espécie. As gaiolas onde estavam as cobaias, os ratos e os camundongos foram forradas com maravalha, a qual foi trocada em dias alternados.

Os animais recebiam água à vontade trocada diariamente e ração, também à vontade, na forma de pelets, para os experimentais contendo $10 \%$ de A. glazioviana e para os testemunhas contendo $10 \%$ de azevém (Lolium multiflorum). Para os coelhos e cobaias também foi oferecido diariamente aveia (Avena sativa) verde, com exceção dos primeiros dias de experimento, quando receberam somente a ração para que ocorresse a adaptação.

A. glazioviana foi colhida de duas árvores existentes na Universidade Federal de Pelotas, onde foram separadas apenas as folhas, secadas à sombra e posteriormente trituradas para a confeç̧ão dos pelets. $O$ azevém utilizado foi proveniente de dois locais: uma parte foi colhida em uma pastagem da Embrapa-Centro de Pesquisa Agropecuária de Clima Temperado, Pelotas, e secado à sombra; a outra parte foi obtida na forma de feno da região de Bagé, também posteriormente triturado. 
Os pelets foram feitos, passando em um utensílio manual de fazer nhoques, uma mistura na proporção de $700 \mathrm{~g}$ de ração comercial para coelhos moída, $200 \mathrm{~g}$ de amido de milho, $1000 \mathrm{ml}$ de água destilada e $100 \mathrm{~g}$ de planta. Posteriormente foram colocados para secar em estufa a $100^{\circ} \mathrm{C}$, por 16 a 20 horas. Após saírem da estufa, esperava-se esfriar e depois eram acondicionados em sacos de papel até serem oferecidos aos animais, à vontade.

Os animais foram observados diariamente por 4 meses, atentando-se para algum tipo de alteração de comportamento ou manifestação de sinal clínico. No período final do experimento, da $14^{\mathrm{a}}$ a $18^{\mathrm{a}}$ semana, realizou-se a pesagem semanal dos animais. Ao final deste período foram sacrificados, os coelhos com a utilização de choque elétrico e as cobaias, ratos e camundongos através da inalação de éter etílico. Foram realizadas necropsias e coletados coração, pulmão, fígado, baço, rim, adrenal, útero, ovário, intestino delgado, intestino grosso, estômago, linfonodos, bexiga e músculo esquelético (semitendinoso ou semimembranoso direito). Os órgãos foram examinados macroscopicamente e fragmentos fixados em formol a $10 \%$ foram processados rotineiramente para histopatologia e corados pela Hematoxilina-Eosina (HE) para análise microscópica. Cortes de coração foram corados pelas técnicas de Gomori e Van Gieson para observação de colágeno.

\section{Efeito abortivo em ratos}

Foi feita, também, a tentativa de reproduzir a forma abortiva da intoxicação por A. glazioviana, utilizando ratos, mediante a administração da planta secada à sombra e moída, na concentração de $10 \%$ na ração, na forma de pelets, nos dois últimos terços da gestação. Os pelets foram preparados da mesma forma que os utilizados no experimento para testar a cardiotoxicidade da planta. Foi considerado o dia zero da gestação o dia em que se observou a presença de espermatozóides no lavado vaginal. Foram utilizados 11 ratos, os quais passaram a receber a ração com a planta a partir do $7^{\circ}$ dia de gestação. Um grupo controle, de 11 fêmeas, recebeu a ração com $10 \%$ de azevém, durante o mesmo período.

Para conhecer a data do acasalamento, os machos foram colocados nas gaiolas com as fêmeas à tardinha (um macho e duas fêmeas em cada gaiola) e separados na manhã seguinte. Imediatamente após a retirada dos machos das gaiolas, procedia-se ao lavado vaginal para a confirmação da prenhez. Este era realizado utilizando-se uma micropipeta ajustável de 10 a 50 microlitros, injetando no canal vaginal 50 microlitros de solução salina a $\mathbf{0 , 9 \%}$ (4,5g de cloreto de sódio e $500 \mathrm{ml}$ de água destilada). Tinha-se o cuidado de não introduzir muito a ponteira da pipeta para evitar a pseudoprenhez. O lavado era colocado em lâmina e posteriormente observado em microscopia de luz, a fim de evidenciar a presença de espermatozóides. Esse dia considerou-se como o dia zero de gestação (Vickery \& Bennett 1970).

\section{Toxicidade da planta seca em ovino}

Como todos os animais de laboratório receberam a planta na forma de pelets, os quais necessitam ser secados em estufa a $100^{\circ} \mathrm{C}$ para evitar a proliferação de fungos, foi testada a toxicidade da planta em um ovino, após passagem da mesma em estufa na mesma temperatura e pelo mesmo período (16-20 horas), a fim de verificar se não havia ocorrido a inativação do princípio ativo. Para isso, as folhas de $A$. glazioviana foram colocadas à sombra para secar e posteriormente na estufa (pelo mesmo período e na mesma temperatura utilizada na secagem dos pelets), trituradas e administradas ao ovino. Este animal recebeu, diariamente, por 26 dias, a dose correspondente a $10 \mathrm{~g} / \mathrm{kg}$ de planta verde, calculada a partir da secagem de $1000 \mathrm{~g}$ da planta verde que resultou em 265,34 g de planta seca. A quantidade de ração oferecida foi correspondente a $1 \%$ do peso vivo incluindo a planta seca triturada, ou seja, para um ovino de $35 \mathrm{~kg}$ foi dada uma mistura de $257 \mathrm{~g}$ de ração comercial para ovinos e $93 \mathrm{~g}$ de planta seca. Essa mistura foi ingerida de forma espontânea por 10 dias. A partir daí o animal recusou-se a comer a ração com a planta por 4 dias, a qual passou a ser administrada diluída em água com a utilização de garrafa por mais 16 dias, totalizando 26 dias de administração da planta. Desde o início foi oferecido água à vontade, capim quicuio (Pennisetum clandestinum) verde cortado e feno de alfafa, sendo este último sempre rejeitado pelo animal. Nos últimos 18 dias de experimento, incluindo os 7 dias em que a ovelha permaneceu sem receber a planta antes de ser sacrificada, foi oferecida ração comercial para ovinos na proporção de $2 \%$ do peso vivo. Durante todo o período experimental foram verificados os sinais clínicos em dias intercalados, inclusive após o animal ser exercitado. Fragmentos dos diferentes órgãos foram coletados, fixados em formol a $10 \%$ e depois processados rotineiramente e os cortes corados pela técnica de HE. Cortes do coração foram corados também pelas técnicas de Gomori e Van Gieson para colágeno. Para o estudo histológico do sistema nervoso foram realizados cortes transversais de córtex, cápsula interna e núcleos da base, tálamo e hipotálamo, mesenséfalo à altura do colículo rostral, cerebelo e pedúnculos cerebelares, ponte, e bulbo.

\section{RESULTADOS}

\section{Efeito cardiotóxico em animais de laboratório}

Todos os animais (coelhos, cobaias, ratos e camundongos) testados para a forma cardíaca da intoxicação por $A$. glazioviana, que receberam ração com $10 \%$ da planta, não apresentaram qualquer alteração clínica evidente durante os quatro meses de experimento. Não houve diferença significativa no ganho de peso entre os grupos tratados e os grupos controles no período avaliado. Nas necropsias e no exame histológico não foram encontradas lesões.

\section{Efeito abortivo em ratos}

Os ratos que ingeriram $A$. glazioviana na ração, na concentração de $10 \%$, e os animais do grupo testemunha pariram normalmente fetos viáveis, no período previsto.

\section{Toxicidade da planta seca em ovino}

0 ovino apresentou sinais de inquietação entre o $7^{\circ}$ e o $14^{\circ}$ dia de experimento. No $15^{\circ}$ dia a ovelha não apresentava arritmia cardíaca, porém o coração apresentava batimentos cardíacos mais fortes. A partir do $22^{\circ}$ dia de experimento, apresentou dispnéia, taquicardia e arritmia cardíacas, que se acentuavam após o exercício. Comia pouco verde e ração, bebia bastante água, tornou-se apática e passava a maior parte do tempo deitada dentro da baia. No período final do experimento apresentava bradicardia e arritmia cardíacas acentuadas. Foi sacrificada e necropsiada 7 dias após ter cessado a administração da planta. Na necropsia observou-se ascite e hidrotórax intensos, coração com áreas esbranquiçadas na forma de estrias em ambos os ventrículos e fígado de coloração clara. A ovelha apresentava prenhez, com feto aparentemente viável, sem autólise, com 2,5 a 3 meses de gestação.

As alterações observadas no exame histológico dos órgãos coletados do ovino limitaram-se ao coração e ao fígado. 
No coração observavam-se áreas multifocais com perda de eosinofilia e fibras cardíacas degeneradas e necróticas. Entre as fibras que haviam perdido a eosinofilia observavam-se, também, fibras vacuolizadas e algumas com maior eosinofilia. Muitas fibras apresentavam-se tumefeitas, com perda da estriação. Alguns núcleos apresentavam aspecto vesiculoso. Em outras áreas o sarcoplasma apresentava aspecto granular e havia desaparecimento de núcleos. Havia proliferação de tecido conjuntivo fibroso presença de macrófagos e células mononucleares. Pelas colorações de Gomori e Van Gieson evidenciava-se abundante produção de colágeno nestas regiões, bem como ao redor dos vasos sanguíneos.

No fígado foram observados focos de congestão, mais frequientes na região centrolobular. Os hepatócitos da área centrolobular apresentavam-se tumefeitos, outros estavam vacuolizados e alguns apresentavam glóbulos hialinos no citoplasma (citossegrossomas). Alguns hepatócitos isolados apresentavam-se necróticos. Havia ainda discreta proliferação de tecido conjuntivo fibroso, principalmente nos espaços porta. No sistema nervoso central observou-se degeneração esponjosa (status spongiosus) da substância branca do cerebelo, pedúnculos cerebelares e ponte.

\section{DISCUSSÃO}

Os resultados deste estudo indicam que animais de laboratório não são susceptíveis à intoxicação por Ateleia glazioviana pela via oral, já que não foi possível a reprodução experimental da forma cardíaca nem da forma abortiva da doença. Os coelhos, cobaias, ratos e camundongos que receberam, por 4 meses, ração com $10 \%$ de A. glazioviana, na tentativa de reproduzir a forma cardíaca da doença, não apresentaram quaisquer alterações clínicas nem lesões macroscópicas ou microscópicas características. Os ratos, fêmeas prenhes, que receberam ração com $10 \%$ de $A$. glazioviana nos dois últimos terços da gestação, tiveram filhotes normais e no período previsto. Em relação às quantidades da planta ingeridas pelos ratos, somente é possível fornecer estimativas. Estimando-se que os animais de laboratório ingerem, diariamente, quantidades de ração equivalentes a $4 \%$ do seu peso vivo, a dose diária de planta seca administrada foi de $4 \mathrm{~g} / \mathrm{kg}$, o que representa, aproximadamente, $16 \mathrm{~g} / \mathrm{kg}$ de planta verde. Certamente, a falta de toxicidade da planta para os animais de laboratório testados não se deve a uma perda de toxicidade durante o processo de secagem dos pelets. Isto por que a planta tratada da mesma forma que a utilizada para fazer os pelets foi administrada a uma ovelha, que apresentou lesões características da forma cardíaca da enfermidade. Em um trabalho anterior foi demonstrado que $A$. glazioviana verde causa sinais clínicos em ovinos nas doses diárias de 5 a $15 \mathrm{~g} / \mathrm{kg}$ de peso vivo em períodos de 13 a 60 dias, sendo que dois ovinos receberam $10 \mathrm{~g} / \mathrm{kg}$ diariamente em 18 e 33 administrações (Stigger et al. 2001). Essa quantidade de planta verde é semelhante à que recebeu o ovino utilizado nesse experimento (26 doses de $2,65 \mathrm{~g} / \mathrm{kg}$ de planta seca administradas diariamente) após a passagem da planta em estufa. Esses resultados confirmam que a planta mantém a toxicidade após ser submetida a temperaturas de $100^{\circ} \mathrm{C}$, por 16 a 20 horas.

A não susceptibilidade dos animais de laboratório à ação cardiotóxica foi constatada, também, nas plantas do sul da África que causam uma doença conhecida como gousiekte, caracterizada por fibrose e insuficiência cardíacas (Kellerman et al. 1988). De uma dessas plantas (Pavetta harborii) foi identificada, como princípio ativo, uma substância denominada pavetamina, pertencente ao grupo das poliaminas, que é um inibidor da síntese protéica, principalmente no coração (Fourie et al. 1995, Schultz et al. 2001). Os efeitos sobre a síntese proteica foram testados em ratos, injetando pavetamina intraperitonealmente (Schultz et al. 2001). A administração dessa substância pela via oral não tem efeito tóxico devido, provavelmente, a sua inativação no estômago dos monográstricos (Anitra Schultz, Division of Toxicology, Onderstepoort Veterinary Institute, South Africa, 2001, comunicação pessoal). Experimentalmente, em ovinos e caprinos, gousiekte pôde ser induzida por via intravenosa, eliminando a suspeita de que a toxina pudesse ser formada a partir de um precursor no rúmen (Fourie et al. 1995). Outras plantas que causam gousiekte incluindo Pachystigma pygmaeum, Fadogia homblei e Pavetta schumanniana contém, também, princípios ativos semelhantes (Fourie et al. 1995). A semelhança na falta de susceptibilidade para animais de laboratório entre $A$. glazioviana e as plantas do sul da África que causam gousiekte sugerem a possibilidade de que $A$. glazioviana contenha um princípio ativo semelhante. Esta hipótese é sugerida pelo fato de que o princípio ativo das plantas que causam gousiekte é termo-estável o que ocorre, também, com o princípio ativo de $A$. glazioviana. No entanto, as plantas cardiotóxicas do sul da África não apresentam, aparentemente, o efeito abortivo para bovinos nem ictiotóxico, presente em $A$. glazioviana. É provável, também, que as diferentes ações de A. glazioviana (cardiotóxica, abortiva e ictiotóxica) sejam causadas por substâncias distintas.

A observação de sinais nervosos e degeneração esponjosa do sistema nervoso central no ovino intoxicado com a planta a $100^{\circ} \mathrm{C}$, sugere que o quadro nervoso causado por A.glazioviana em bovinos (Gava \& Barros 2001, Gava et al. 2001) e ovinos (Stigger et al. 2001) é causado pelo mesmo princípio ativo que causa cardiomiopatia.

Neste experimento não foi possível constatar o efeito abortivo da planta em ratos. Esses resultados diferem dos obtidos mediante a administração, por via oral, de extratos aquosos e hidroalcoólicos de A. glazioviana a ratas, do primeiro ao último dia de gestação (Langeloh et al. 1992), ou por inoculação, também em ratas gestantes, via intraperitoneal, do extrato hidroetanólico das folhas da planta (Marona et al. 1992). Nesses experimentos houve redução do desenvolvimento ponderal das gestantes, reabsorção embrionária e aborto. Considerando a redução no desenvolvimento ponderal, torna-se difícil estabelecer se o efeito abortivo foi causado especificamente por algum dos constituintes da planta ou se esteve associado a um comprometimento sistêmico associado a efeito tóxico geral. Considerando que nesses tra- 
balhos os extratos foram produzidos com folhas da planta secadas à sombra e sem calor, é possível que esses efeitos tenham sido causados por uma substância termolábil, que no nosso trabalho tenha sido destruída pelo calor durante $o$ processo de produção dos pelets.

A. glazioviana é uma planta comprovadamente causadora de abortos em bovinos (Stolf et al. 1994, Gava \& Barros 2001). Em nosso experimento, a planta foi administrada a um ovino prenhe em 26 doses diárias correspondentes a $10 \mathrm{~g} / \mathrm{kg}$ de planta verde, que, embora tenha apresentado severa insuficiência cardíaca, não abortou. Stigger et al. (2001) constaram esse mesmo fato em um ovino intoxicado experimentalmente, que recebeu 13 administrações diárias de planta seca, equivalente a $10 \mathrm{~g} / \mathrm{kg}$ de planta verde, e quando foi sacrificado, apresentando sinais clínicos avançados de insuficiência cardíaca, tinha um feto de três meses com aspecto normal. Em bovinos ocorrem abortos e nascimento de bezerros fracos com doses de 23 a $35 \mathrm{~g} / \mathrm{kg}$, em doses únicas ou fraccionadas (em 3 a 4 dias), de $A$. galzioviana verde, o seu equivalente em planta seca (Stolf et al. 1994). Esses resultados sugerem que os ovinos não são susceptíveis, ou são menos sensíveis que os bovinos à ação abortiva da planta. No entanto, deve considerar-se a possibilidade de que o princípio ativo da planta que causa aborto seja um composto diferente do que causa insuficiência cardíaca e sinais nervosos, que no nosso experimento tenha sido destruído pelo calor no processo de produção dos pelets. Esta possibilidade foi evidenciada, também, em experimentos recentes, nos quais A. glaziovina seca a $100^{\circ} \mathrm{C}$ não causou abortos em bovinos, mas lesões cardíacas e nervosas nos bezerros, que ocorreram em consequiência da passagem do princípio ativo através da placenta (A. L. Schild, G. Riet-Correa \& F. Riet Correa, Universidade Federal de Pelotas, 2001, dados não publicados).

Duas espécies de Tetrapterys, T. multiglandulosa e T. acutifolia, causam abortos, sinais nervosos e insuficiência cardíaca em bovinos (Tokarnia et al. 1989, Tokarnia et al. 2000) muito semelhantes aos observados na intoxicação por A. glazioviana, o que sugere que os dois gêneros contenham princípios tóxicos semelhantes. Experimentalmente, foi demostrado que Tetrapterys spp causam fibrose cardíaca e degeneração esponjosa do sistema nervoso central em ovinos (G. Riet-Correa, A. L. Schild \& F. Riet-Correa, Universidade Federal de Pelotas, dados não publicados).

Antes de ser conhecida a toxicidade de A. glazioviana para bovinos foi relatada a atividade ictiotóxica da planta (Ortega $\&$ Schenkel 1987). As plantas ictiotóxicas, conhecidas no Brasil como timbó, são espécies que, por causarem a morte ou a imobilização dos peixes, têm sido utilizadas pelos nativos para pescar. Plantas ictiotóxicas contém diferentes princípios ativos. Um grupo (Lonchocarpus, Derris, Tephrosia) apresenta rotenona como princípio ativo (Moretti \& Grenand 1982, Ibrahim et al. 2000). Outro grupo (Thinouia, Serjania) contém saponinas (Moretti \& Grenand 1982, Teixeira et al. 1984, Schenkel et al. 1991). Sesquiterpenos são encontrados em Dittrichia graveolens (Lanzetta et al. 1991), triterpenoides em Belamcanda chinensis (Ito et al. 1999) e derivados de floroglucinol em Dryopteris fragrans (Ito et al. 2000). Tephrosia linearis, pertencente ao grupo de plantas ictiotóxicas que contém rotenona e apresenta propriedades abortivas para vacas prenhes (Petitjean et al. 1993, citado por Ibrahim et al. 2000). Ortega \& Schenkel (1987) demonstraram as propriedades ictiotóxicas do extrato etanólico das folhas e raízes de A. glazioviana. No estudo químico da planta não foram encontradas saponinas com propriedades ictiotóxicas. Dos extratos das folhas da planta foram isolados como principais componentes isoflavonas (afrormosina e 5-metoxiafrormosina), além de rutina, flavonóides, taninos, triterpenos/ esteróides e aminoácidos. No entanto, a ictiotoxicidade não foi relacionada a nenhum desses compostos (Ortega \& Schenkel 1986).

\section{REFERÊNCIAS}

Fourie N., Erasmus G.L., Schultz R. A. \& Prozesky, L. 1995. Isolation of the toxin responsible for gousiekte, a plant-induced cardiomyopathy of ruminants in Southern Africa. Onderstepoort J. Vet. Res. 62:77-87.

Fourie N., Schultz R.A., Prozesky L., Kellerman T.S. \& Labuschagne L. 1989. Clinical pathological changes in gousiekte, a plant-induced cardiotoxicosis of ruminants. Onderstepoort J. Vet. Res. 56:73-80.

Gava A. \& Barros C.S. L. 2001. Field observations of Ateleia glazioviana poisoning in cattle in Southern Brazil. Vet. Human Toxicol. 43:37-41.

Gava A., Barros C.S.L., Pilati C., Barros S.S. \& Mori A.M. 2001. Intoxicação por Ateleia glazioviana (Leg. Papilionoideae) em bovinos. Pesq. Vet. Bras. 21:4959.

Ibrahim B., M'batchi B., Mounzeo H., Bourobou H.P. \& Posso P. 2000. Effect of Tephrosia vogelli and Justicia extensa on Tilapia nilotica in vivo. J. Ethnopharmacol. 69:99-104.

Ito H., Muranaka T., Mori K., Jin Z.X., Tokuda H., Nishino H. \& Yoshida T. 2000. Ichthyotoxic phloroglucinol derivatives from Dryopteris fragrans and their anti-tumor promoting activity. Chem. Pharmac. Bull. 48:1190-1195.

Ito H., Onoue S., Miyake Y. \& Yoshida T. 1999. Iridal-type triterpenoides with ichthyotoxic activity from Belamcanda chinensis. J. Nat. Prod. 62:89-93.

Kellerman T.S., Coetzer J.A. \& Naudé T.W. 1988. Plant Poisonings and Mycotoxicoses of Livestock in Southern Africa. Oxford University Press, Cape Town, p. 83-130.

Langeloh A., Leguizanón F. \& Dalsenter P. 1992. Potencial abortivo e infertilizante de plantas brasileiras contaminantes ocasionais de pastagens de bovinos e outros herbívoros de interesse econômico. Pesq. Vet. Bras. 12:11-18.

Lanzetta R., Lama G., Mauriello G., Parrilli M., Racioppi R. \& Sodano G. 1991. Ichthyotoxic sesquiterpenes and xanthanolides from Dittrichia-Graveolens Phytochem. 30:1121-1124.

Marona H.R.N., Langeloh A. \& Schenkel E.P. 1992. Atividade abortiva de Ateleia glazioviana (Leg. Papilionoideae) em ratas. Pes. Vet. Bras. 12:81-83.

Moretti C. \& Grenand P. 1982. The "nivres" or ichthyotoxic plants of French Guyana. J. Ethnopharmacol. 6:139-160.

Ortega G.G. \& Schenkel E.P. 1987. Ichtyotoxic activities of Ateleia glazioviana Baill and Thinouia coriaceae. Brit. J. Ethnopharmacol. 20:81-84.

Ortega G.G. \& Schenkel E.P. 1986. Isoflavonas de Ateleia glazioviana Baill (Leguminosae). Cadernos de Farmacologia 2:133-161.

Schenkel E.P., Werner W. \& Schulte K.E. 1991. Saponins from Thinouia coriaceae. Planta Médica 57:463-467.

Schultz R.A., Fourie N., Bode M.L., Basson K.M., Labuschagne L., Vleggaar R. \& 
Medlen C. 2001. Pavetamine: an inhibitor of protein synthesis in the heart. $6^{\text {th }}$ International Symposium on Poisonous Plants, Glasgow, Scotland, s/p. (Abstract)

Stigger A.L., Barros C.S.L., Langohr I. M. \& Barros S.S. 2001. Intoxicação experimental por Ateleia glazioviana (Leg. Papilionoideae) em ovinos. Pesq. Vet. Bras. 21:98-108.

Stolf L., Gava A., Varaschin M.S., Neves D.S., Mondadori A.J. \& Scolari, L.S. 1994. Aborto em bovinos causado pela ingestão de Ateleia glazioviana (Leg. Papilionoideae). Pesq. Vet. Bras. 14:15-18.
Teixeira J.R., Lapa A.J. Souccar C. \& Valle J.R. 1984. Timbos: ichthyotoxic plants used by Brazilian indians. J. Ethnopharmacol. 10:311-318.

Tokarnia C.H., Peixoto P.V., Döbereiner J., Consorte L.B. \& Gava A. 1989. Tetrapterys spp (Malpighiaceae), a causa de mortandades em bovinos caracterizadas por alterações cardíacas. Pesq. Vet. Bras. 9:23-44.

Vickery B.H. \& Bennett J.P. 1970. Rats and mice, p.229-315. In: Hafez E.S.E. (ed.) Reproduction and Breeding Techniques for Laboratory Animals. Lea \& Febiger, Philadelphia. 